LA GRANA:

REVISTA DE

CIENCIAS DE LA VIDA

pISSN:1390-3799; eISSN:1390-8596

http:/ / doi.org/10.17163/lgr.n34.2021.09
Artículo científico / Scientific paper

BioteCNOLOGÍA

(c) (1) (2) (2)

\title{
INDUCCIÓN IN VITRO DE CALLOS A PARTIR DE EXPLANTES FOLIARES EN ROCOTO (Capsicum pubescens Ruiz E Pav.)
}

\author{
IN VITRO INDUCTION OF CALLUS FROM FOLIAR EXPLANTS IN ROCOTO \\ (Capsicum pubescens Ruiz \& Pav.)
}

\section{Angel David Hernández-Amasifuen*®, Alexis Argüelles-Curaca ${ }^{*}$, Anthony Apolinario Cortez-Lázaro y Hermila Belba Díaz-Pillasca}

\begin{abstract}
Laboratorio de Biotecnología Vegetal, Escuela Profesional de Biología con mención en Biotecnología. Universidad Nacional José Faustino Sánchez Carrión, Av. Mercedes Indacochea N 609, Huacho, Perú.

*Autor para correspondencia: adhernandz@hotmail.com
\end{abstract}

\begin{abstract}
Resumen
El rocoto (Capsicum pubescens Ruiz \& Pav.) es una planta oriunda de Perú, empleada en la gastronomía nacional, tiene un gran valor nutricional, y presenta propiedades farmacéuticas y medicinales. El cultivo es susceptible a enfermedades causada por fitopatógenos, los cuales son diseminados por semillas de cultivares o almácigos infectados. Mediante el uso de herramientas biotecnológicas como el cultivo de tejidos vegetales in vitro se puede obtener plantas libres de patógenos, de buena calidad y de gran potencial agronómico. Por lo tanto, el presente trabajo se planteó como objetivo desarrollar una metodología para la inducción in vitro de callos a partir de hojas en rocoto. Se emplearon plántulas de rocoto germinadas in vitro, de las cuales se seleccionaron las primeras hojas verdaderas que fueron seccionadas en explantes de $1 \mathrm{~cm}$ y colocadas en diferentes medios de cultivo MS adicionadas con ácido 2,4-diclorofenoxiacético (2,4-D). Se evaluó la respuesta de inducción a callogénesis en cinco tratamientos con diferentes concentraciones de

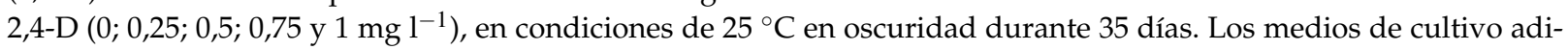

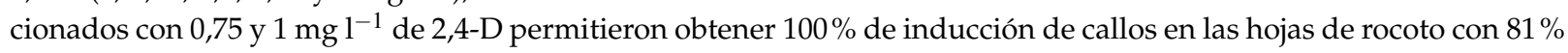
y $86 \%$ respectivamente de formación de callos de grado 3. Este estudio, pionero para la especie, abre expectativas en programas de mejoramiento para su potencial uso.
\end{abstract}

Palabras clave: Biotecnología, tejido vegetal, callogénesis, hojas, germinación. 


\begin{abstract}
Rocoto (Capsicum pubescens Ruiz \& Pav.) is a native plant of Peru, used in the national gastronomy with great nutritional value; it has pharmaceutical and medicinal properties. The crop is susceptible to diseases caused by phytopathogens, which are spread by seeds of infected cultivars or seedlings. Through the use of biotechnological tools such as in vitro plant tissue culture, it is possible to obtain plants free of pathogens, of good quality and great agronomic potential. Therefore, the present work aimed to develop a methodology for the in vitro induction of callus from hot pepper leaves. In vitro germinated rocoto seedlings were used, from which the first true leaves were selected, which were sectioned into $1 \mathrm{~cm}$ explants and placed in different MS culture media added with 2,4-dichlorophenoxyacetic acid (2,4-D). The induction response to callogenesis was evaluated in five treatments with different concentrations of 2,4-D $\left(0,0.25,0.5,0.75\right.$ and $\left.1 \mathrm{mg} \mathrm{l}^{-1}\right)$, under conditions of $25^{\circ} \mathrm{C}$ in the dark for 35 days. The culture media added with 0.75 and $1 \mathrm{mg} \mathrm{l}^{-1}$ of 2.4-D allowed to obtain $100 \%$ induction of calluses in the hot pepper leaves with $81 \%$ and $86 \%$, respectively of grade 3 callus formation. This study, pioneer for the species, is good for the potential use of breeding programs.
\end{abstract}

Keywords: Biotechnology, plant tissue, callogenesis, leaves, germination.

Forma sugerida de citar: Hernández-Amasifuen, A., Argüelles-Curaca, A., Cortez-Lázaro, A.A. y Díaz-Pillasca, H.B. (2021). Inducción in vitro de callos a partir de explantes foliares en rocoto (Capsicum pubescens Ruiz \& Pav.). La Granja: Revista de Ciencias de la Vida. Vol. 34(2):131-140. http://doi.org/10.17163/lgr.n34.2021.09.

\title{
IDs Orcid:
}

Angel David Hernández-Amasifuen: http:/ /orcid.org/0000-0001-8267-409X

Alexis Argüelles-Curaca: http:/ / orcid.org/0000-0002-6022-9099

Anthony Apolinario Cortez-Lázaro: http:/ / orcid.org/0000-0002-4812-4307

Hermila Belba Díaz-Pillasca: http:/ /orcid.org/0000-0002-2491-3774 


\section{Introducción}

El rocoto (Capsicum pubescens Ruiz \& Pav.) es una planta herbácea con ciclo de vida perenne que pertenece a la familia Solanaceae. Su centro de origen es la región andina de Perú, siendo posible encontrarse de manera silvestre en la sierra y selva alta. Esta especie se diferencia de las demás especies que pertenecen al género Capsicum por presentar flores con coloración púrpura o morada y por sus semillas de color negro. El fruto puede variar en forma, tamaño y color, pero se caracteriza por su picor y por esta razón es muy empleado en la gastronomía peruana. Además, el rocoto presenta propiedades farmacéuticas y medicinales, relacionadas a la capsaicina (Caballero, Márquez y Rojano, 2017).

En Perú se han definido dos variedades de rocoto, el rocoto de monte y el rocoto de huerta o serrano. El rocoto de monte es denominado de esta manera por ser cultivado en mayor parte en la selva central, presenta mayor tamaño de fruto, por lo cual existe una mayor demanda de esta variedad para la preparación del rocoto relleno. La otra variedad es el rocoto de huerta o serrano, cultivado en todas las regiones del país, mayormente en los valles andinos. El fruto de esta variedad es de menor tamaño, pero con un característico picor fuerte que se utiliza para salsas (Valdez, 2017).

La producción nacional de rocoto ha ido incrementando con una tasa anual del $5 \%$ principalmente por la gran demanda gastronómica que se viene desarrollando en país; debido a esto se considera en la actualidad como un producto de importancia nacional (Sardón, 2015). Pero también se debe considerar que este cultivo presenta susceptibilidad a la marchitez, pudrición radicular y entre otras enfermedades causadas por Fusarium oxysporum, Phytoptora capsici, Risotonia solanacearum y entre otros fitopatógenos. También es susceptible a daños causados por virus que pueden llegar a causar amarillamiento en las nervaduras, deformaciones en hojas y frutos, enanismo, falta de vigor y caída de las hojas. La principal causa de la diseminación de estas enfermedades son las semillas provenientes de cultivares o almácigos infectados, debido que en este cultivo normalmente se emplean semillas de campañas o sembríos anteriores, y en el caso de algunos virus se diseminan al contacto entre plantas (Lucana, 2012; Hernández, Pineda y Noriega, 2019).
Es importante fortalecer la cadena de valor del rocoto, razón por la cual se busca obtener semillas de calidad y certificadas, o plántulas libres de patógenos para poder mantener cultivos más uniformes que presenten mayor calidad y producción. Dentro de las alternativas para la obtención de material vegetal aséptico se consideran a las herramientas biotecnológicas, con el empleo de técnicas de cultivo de tejidos vegetales in vitro (Robledo y Carrillo, 2004; Sanatombi y Sharma, 2007; Orlinska y Nowaczyk, 2015). Estas técnicas permiten la proliferación de células a partir de un explante (fragmento vegetal que puede ser meristemos, yemas axilares, hojas, raíces, anteras e incluso microsporas) en un medio de cultivo provisto de nutrientes, vitaminas, y en algunos casos también de hormonas (Levitus y col., 2010; Vélez y col., 2010; Venkataiah y col., 2016). Estos explantes, en condiciones apropiadas, inducirán a la formación de callos, que son masas amorfas o desorganizadas de células indiferenciadas. La importancia del callo radica en su funcionalidad de crecimiento irregular con potencial para formar órganos o embriones en las condiciones adecuadas (Alayón y col., 2006. Pérez y col., 2009; Terra y col., 2009; Smith, 2012; Rashmi y Trivedi, 2014).

El potencial de los callos como vía para la organogénesis y embriogénesis indirecta es una alternativa para programas de mejoramiento genético en rocoto, debido a que estos métodos en algunas especies o genotipos al ser introducidos en medios de cultivo in vitro con diferentes concentraciones de fitohormonas o combinaciones de estas pueden inducir a variación somaclonal, permitiendo obtener nuevas características o la eliminación de alguna indeseada (Sala y Labra, 2003; Rodríguez y col., 2014). Pero de no presentarse estas variaciones somaclonales se pueden multiplicar genotipos prometedores de buen rendimiento y buena calidad, como se viene desarrollando en el cultivo de tejidos vegetales in vitro en diferentes especies del género Capsicum (Marín, 2012; Gómez, 2016; Gutierrez-Rosati y Vega, 2017; Izquierdo, Alcaraz y Rodríguez-Álvarez, 2017).

Por lo tanto, la presente investigación se planteó el objetivo de desarrollar una metodología para la inducción de callos in vitro a partir de segmentos de hojas en rocoto. 


\section{Materiales y Métodos}

La presente investigación se realizó en las instalaciones del laboratorio de Biotecnología Vegetal de la Escuela Profesional de Biología con mención en Biotecnología, ubicada en la Universidad Nacional José Faustino Sánchez Carrión, Huacho, Lima, Perú.

\subsection{Desinfección del material vegetal}

Se emplearon semillas de rocoto obtenidas a partir de frutos de rocotos maduros presentes en el invernadero perteneciente al laboratorio. Se lavaron las semillas con agua más detergente comercial durante 5 minutos, y luego se continuó con el proceso de desinfección en cámara de flujo laminar empleando el protocolo establecido por Hernández, Pineda y Díaz (2019). Primero se sumergieron las semillas en etanol al $70 \%$ durante 1 minuto, luego se sumergieron en una solución de hipoclorito de sodio al $2 \%$ durante 15 minutos en agitación constante. Transcurrido el tiempo se realizaron tres enjuagues con agua destilada estéril, luego fueron coladas en papel filtro y se colocaron tres semillas por tubo de ensayo con medio de cultivo MS (Murashige y Skoog, 1962).

Todos los tratamientos se mantuvieron en cámara de crecimiento (Plant Growth Chamber, LGC$5201 \mathrm{G}, \mathrm{LabTech}$ ) en condiciones de oscuridad total a $25^{\circ} \mathrm{C}$, con humedad relativa del $75 \pm 2 \%$. Cuando inició la germinación se cambiaron a fotoperiodo de 16 horas de luz y 8 horas de oscuridad.

El medio de cultivo MS estuvo constituido por las sales descritas por Murashige y Skoog (1962), adicionado con mioinositol $\left(100 \mathrm{mg} \mathrm{l}^{-1}\right)$, ácido nicotínico $\left(0,5 \mathrm{mg} \mathrm{l}^{-1}\right)$, piridoxina HCL $\left(0,5 \mathrm{mg} \mathrm{l}^{-1}\right)$, tiamina HCL $\left(0,1 \mathrm{mg} \mathrm{l}^{-1}\right)$, glicina $\left(2 \mathrm{mg} \mathrm{l}^{-1}\right)$ y sacarosa $\left(30 \mathrm{~g} \mathrm{l}^{-1}\right)$, antes de agregar el agar agar $\left(7 \mathrm{~g} \mathrm{l}^{-1}\right)$ se ajustó el pH a 5,7 \pm 0,1 empleando el potenciómetro Lab 850 (SI Analytics). Posteriormente se procedió a esterilizar en autoclave (BKM-Z18N, Biobase) a 1,2 Bar de presión y $121^{\circ} \mathrm{C}$ durante 20 minutos.

\subsection{Inducción de callos}

De las plántulas germinadas in vitro se seleccionaron las dos primeras hojas verdaderas, las cuales fueron segmentadas en explantes de $1 \mathrm{~cm}$ y se introdujeron cinco segmentos por medio de cultivo MS, adicionado con mioinositol $\left(100 \mathrm{mg} \mathrm{l}^{-1}\right)$, ácido nicotínico $\left(0,5 \mathrm{mg} \mathrm{l}^{-1}\right)$, piridoxina $\mathrm{HCL}(0,5 \mathrm{mg}$ $\left.\mathrm{l}^{-1}\right)$, tiamina HCL $\left(0,1 \mathrm{mg} \mathrm{l}^{-1}\right)$, glicina $\left(2 \mathrm{mg} \mathrm{l}^{-1}\right)$ sacarosa $\left(30 \mathrm{~g}^{-1}\right)$ y la auxina $2,4-\mathrm{D}$ en diferentes concentraciones (Tabla 1), seguidamente se ajustó el $\mathrm{pH}$ a 5,7 $\pm 0,1 \mathrm{y}$ se agregó agar agar $\left(7 \mathrm{~g} \mathrm{l}^{-1}\right)$. Posteriormente se esterilizó en autoclave a 1,2 Bar de presión y $121^{\circ} \mathrm{C}$ durante 20 minutos.

Todos los tratamientos se mantuvieron en cámara de crecimiento (Plant Growth Chamber, LGC $5201 \mathrm{G}, \mathrm{LabTech}$ ) en condiciones de oscuridad total a $25^{\circ} \mathrm{C}$ y con humedad relativa del $75 \pm 2 \%$ durante 35 días, con observaciones cada siete días para diferenciar el progreso de inducción.

Tabla 1. Tratamientos para la inducción de callos en hojas de rocoto.

\begin{tabular}{cc}
\hline Tratamiento & $2,4-\mathrm{D}\left(\mathrm{mg} \mathrm{l}^{-1}\right)$ \\
\hline T1 & 0 \\
T2 & 0,25 \\
T3 & 0,5 \\
T4 & 0,75 \\
T5 & 1 \\
\hline 2,4-D = Ácido 2,4-diclorofenoxiacético
\end{tabular}

\subsection{Diseño experimental y análisis estadís- tico}

El diseño fue completamente al azar (DCA) para cinco tratamientos, utilizándose 15 repeticiones por tratamiento; la unidad experimental está constituida por cada segmento de hoja de rocoto. Se evaluó el porcentaje de inducción de callos en hojas de rocoto y el grado de los callos en la escala de Santana (1982) (Tabla 2). Los datos obtenidos se sometieron a Análisis de Varianza (ANVA) y comparación entre las medias con prueba de Tukey ( $\leq \leq 0,05)$; ambos análisis se realizaron con el paquete estadístico agricolae del programa $\mathrm{R}$ (versión 4.0.3 para Windows). 
Tabla 2. Descripción de la escala empleada por Santana (1982).

\begin{tabular}{ccc}
\hline Grado & Inducción de callos & Observación \\
\hline 0 & No formación del callo & - \\
1 & Ligera formación del callo & $\begin{array}{c}\text { Débil proliferación en zonas } \\
\text { del borde del explante } \\
\text { Proliferación de células por } \\
\text { todos los bordes del explante } \\
\text { sin llegar a formar una masa } \\
\text { Formación de una masa } \\
\text { voluminosa de callos }\end{array}$ \\
\hline
\end{tabular}

\section{Resultados}

La metodología empleada para la desinfección de semillas de rocoto permitió obtener $100 \%$ de semillas libres de contaminación en los medios de cultivo, permitiendo la germinación sin problemas por bacterias u hongos que compitan con la plántula en crecimiento.

La inducción de callos a partir de explantes foliares en rocoto se logró apreciar desde el séptimo día en los tratamientos adicionados con 0,75 y $1 \mathrm{mg}$
$1^{-1}$ de 2,4-D (T4 y T5, respectivamente) formando callos de grado 1 . Los tratamientos adicionados con 0,25 y 0,5 $\mathrm{mg} \mathrm{l}^{-1}$ de 2,4-D presentaron la formación de callos en las hojas de rocoto en el transcurso de la segunda semana de introducción en los medios de inducción. Transcurrido los 35 días, los medios de cultivo MS adicionados con 0,75 y $1 \mathrm{mg} \mathrm{l}^{-1}$ de 2,4-D presentaron los mayores porcentajes de formación de callos con $100 \%$ de inducción de callos en hojas de rocoto (Figura 1), presentando diferencias significativas con los demás tratamientos (Figura 2).

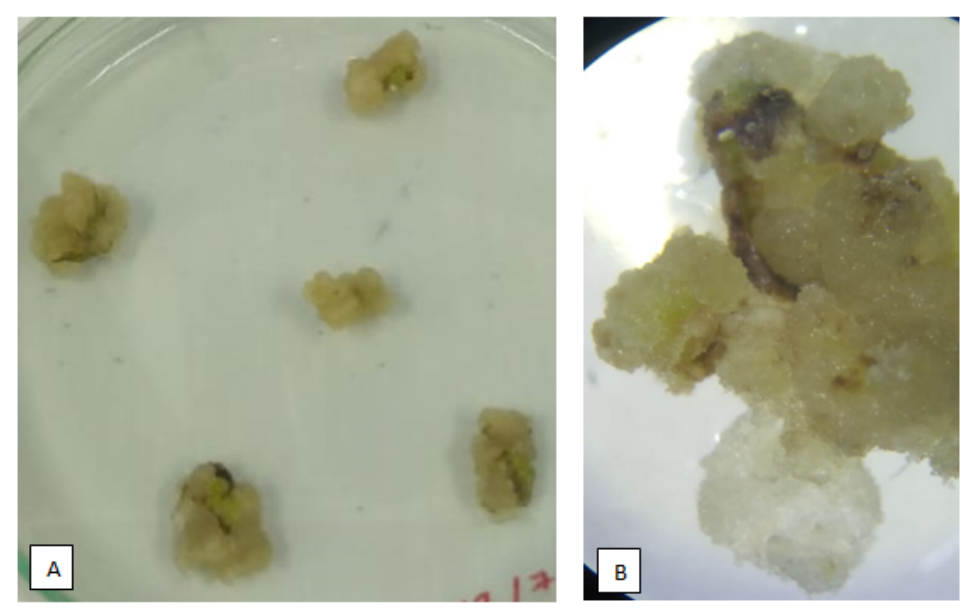

Figura 1. A. Callos a los 35 días formados a partir de hojas de rocoto en medio basal MS con 0,75 mg $1^{-1}$ de 2,4-D. B. Callo inducido a los 35 días con el tratamiento $1 \mathrm{mg} \mathrm{l}^{-1}$ de 2,4-D con coloración crema, zonas translucidas y de consistencia friable.

Los tratamientos con mayores porcentajes de callos de grado 3 fueron los medios de cultivo MS de 0,75 y $1 \mathrm{mg} \mathrm{l}^{-1}$ de $2,4-\mathrm{D}$ con $81 \%$ y $86 \%$, respectivamente; sin embargo, no hubo diferencias significativas entre ambos tratamientos (Tabla 3). Segui- dos del tratamiento de $0,5 \mathrm{mg}^{-1}$ de 2,4 -D con $57 \%$, mientras que el tratamiento de $0,25 \mathrm{mg} \mathrm{l}^{-1}$ de 2,4-D presentó mayor porcentaje de callos pertenecientes al grado 2 . 


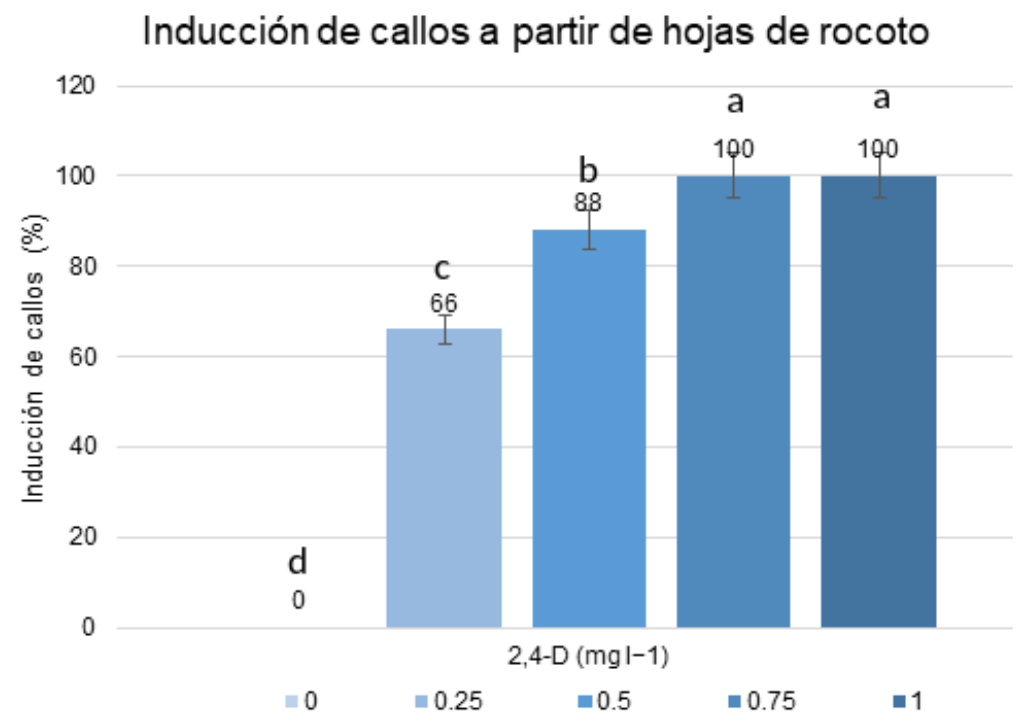

Figura 2. Porcentaje de inducción de callos in vitro a partir de hojas de rocoto. Medias con letras distintas difieren significativamente según prueba de Tukey para $\mathrm{p}<0,05$

Tabla 3. Porcentaje de los grados de formación de callos en hojas de rocoto.

\begin{tabular}{ccccc}
\hline & \multicolumn{4}{c}{ Formación de callos } \\
Tratamiento & por grado de la escala (\%) \\
& 0 & 1 & 2 & 3 \\
\hline T1 & $100 \mathrm{a}$ & $0 \mathrm{c}$ & $0 \mathrm{c}$ & $0 \mathrm{~d}$ \\
T2 & $0 \mathrm{~b}$ & $18 \mathrm{a}$ & $58 \mathrm{a}$ & $24 \mathrm{c}$ \\
T3 & $0 \mathrm{~b}$ & $7 \mathrm{~b}$ & $46 \mathrm{a}$ & $57 \mathrm{~b}$ \\
T4 & $0 \mathrm{~b}$ & $0 \mathrm{c}$ & $19 \mathrm{~b}$ & $81 \mathrm{a}$ \\
T5 & $0 \mathrm{~b}$ & $0 \mathrm{c}$ & $14 \mathrm{~b}$ & $86 \mathrm{a}$ \\
\hline
\end{tabular}

Medias con letras distintas difieren significativamente según prueba de Tukey para $\mathrm{p}<0,05$.

Las características morfológicas de los callos fueron de color crema amarillo y en algunos explantes presentaron zonas blanquecinas o translucidas, y la consistencia de los callos fue friable. Los callos iniciaron su formación en los sitios de corte (bordes) de los explantes, llegando a cubrir por completo la superficie de los explantes en los tratamientos T3 y T4. Por lo que se puede indicar que el rocoto tiene buena respuesta a la inducción de callos, en rápida formación y crecimiento (Figura 3).

\section{Discusión}

Se logró inducir en los explantes foliares de rocoto la formación de callos in vitro con los medios de cultivo MS con presencia de 2,4-D, la apariencia de los callos fue translucida y compacta. La inducción de callos a partir de hojas dentro del género Capsicum es muy favorable en comparación a otros tipos de explantes (Solís-Ramos y col., 2010; Alva-Guzmán, Cerna-Rebaza y Chico-Ruíz, 2014; Argüelles y col., 2020). Tal como afirma Rodríguez y col. (2014) y Espinosa y col. (2012), la inducción de callos en el caso de las hojas es altamente dependiente del tipo de explante y hormona empleada, y a diferencia de otros explantes, se ve un claro incremento de callos cuando se aumenta la concentración de 2,4-D, además de que este tipo de hormona influye en el aspecto de los callos.

La adición de auxinas y su concentración en el medio de cultivo puede generar un mayor porcentaje de inducción de callos dependiendo de la especie o genotipo empleado, pero la acción de las auxinas está relacionada a la presencia de compuestos presentes en el medio de cultivo que tienen mayor influencia en el desarrollo y diferenciación celular (Feeney y col., 2007; Meiners, Schwab y Szankows$\mathrm{ki}, 2007)$. Esto debido a que en el cultivo in vitro estos compuestos endógenos presentan cambios drásticos en el ambiente celular, lo que genera efecto de estrés que puede causar una reorganización celular y formar una masa de células no diferenciadas (Feher, Pasternak y Dudits, 2003; Shriram, Kumar y Shitole, 2008). 
Los callos que se fueron generando en las primeras semanas iniciaron en los bordes de los explantes, y progresaron gradualmente en el explante con el transcurso de los días. En el día 35 los explantes se encontraban cubiertos y hubo un incremento en el tamaño de los callos. Smith (2012), afirma que los callos se generan a partir de la zona de corte de los explantes, zona que está en contacto directo al medio con los reguladores de crecimiento que influyen en una acumulación de auxinas, estimulando una continua división mitótica que genera la formación de tejido calloso poco a poco hasta cubrir el explante en gran parte o por completo.

El efecto de la auxina 2,4-D sobre los explantes foliares de rocoto resultó en la inducción de callos, lo que podría estar relacionado a las acciones fisiológicas que se activan en el explante por medio de la auxina exógena adicionada en el medio de cultivo. Taiz y Zeiger (1998), determinaron que la inducción se expresa por medio de genes que codifican factores proteicos mediante la unión de las auxinas a receptores externos e internos. Azcón-Bieto (2008), descubrieron que los factores proteicos permiten el aumento de la plasticidad y ablandamiento de la pared celular, resultando en la dilatación de la célula por presión de turgencia, incrementando de tamaño hasta que la pared celular opone re- sistencia. Pero también la inducción de callos está influenciada por enzimas que activan o reprimen la transcripción de genes que median las acciones fisiológicas de las citoquininas; estas enzimas son las histidinas fosfotransferasas, las cuales son activadas por la unión de las citoquininas a receptores tipo histidina quinasas (Müller y Sheen, 2007).

La formación de los callos de rocoto en la primera semana puede ser un hallazgo de importancia porque brinda información de ser una especie de rápido efecto de inducción. Los resultados obtenidos fueron superiores en comparación con los obtenidos por Alva-Guzmán, Cerna-Rebaza y Chico-Ruíz (2014), quienes generaron callos en Capsicum chinensis a partir del décimo día de introducción del explante al medio de inducción, empleando 0,5 y 1 $\mathrm{mg} \mathrm{l}^{-1}$ de 2,4-D.

Se resalta la importancia de la auxina 2,4-D, por ser la principal fitohormona empleada en condiciones in vitro para la inducción de callos, existiendo un gran número de reportes de su adición en los medios de cultivo, tanto para especies del mismo género que el rocoto como para otros géneros (Larson, Gómez y Ríos, 2006; Terra y col., 2009; Hernández y Díaz, 2019; Hernández y col., 2020).
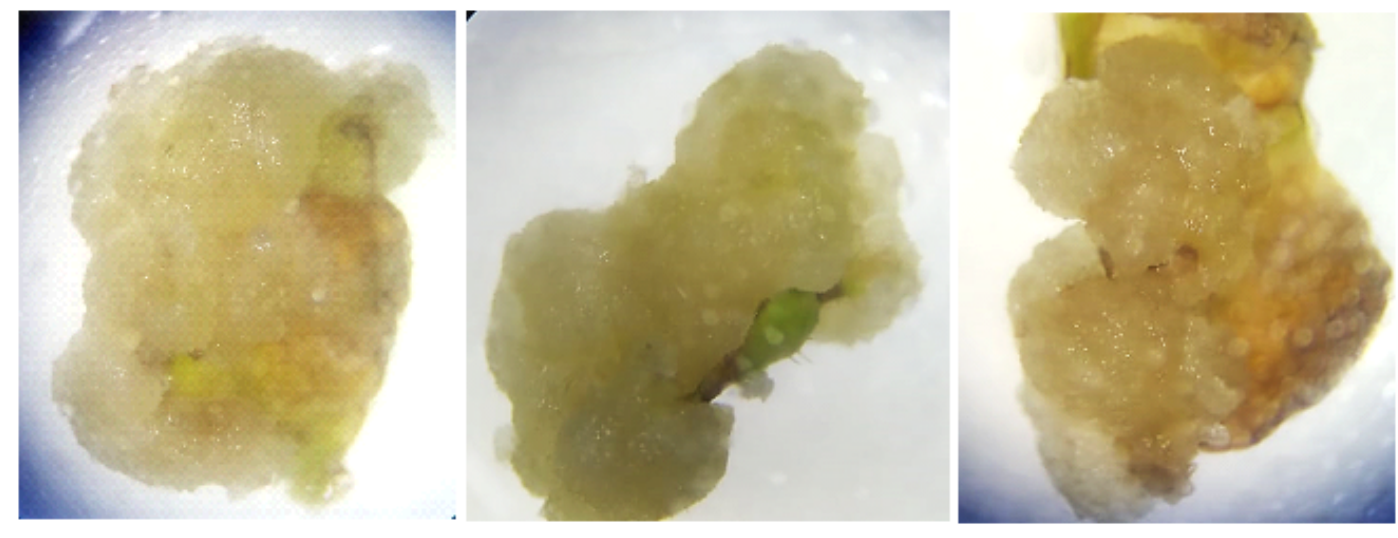

Figura 3. Callos obtenidos en explantes foliares de rocoto, inducidos en medio de cultivo MS con 2,4-D (0,75 mg $\left.1^{-1}\right)$.

También se debe tener en cuenta la edad de los explantes empleados, siendo las primeras hojas verdaderas de rocoto las que influenciaron en el estudio al presentar un mayor potencial de inducción, tal como afirman Alleweldt y Radler (1962), al indicar que la edad fisiológica de los explantes es inversamente proporcional a su potencial organogénico. 
Estos resultados suponen un avance importante en la aplicación de técnicas biotecnológicas en programas de mejoramiento genético de rocoto, presentándose de manera favorable para el potencial uso de callos de esta especie en cultivos celulares para la obtención de metabolitos secundarios de interés farmacológico. De igual forma, es una base para futuras investigaciones en inducción de embriogénesis somática indirecta, organogénesis indirecta, rizogénsis, aislamiento de protoplastos, entre otros.

\section{Conclusiones}

Se desarrollo una metodología para la inducción in vitro de callos a partir de hojas en rocoto, obteniendo el mayor porcentaje de inducción y formación de callos en grado 3, empleando un medio de cultivo MS adicionado con 0,75 y $1 \mathrm{mg}^{-1}$ de 2,4-D.

\section{Referencias}

Alayón, P. y col. (2006.). «Obtención de callos por cultivo in vitro de pulpa de manzana cv'Anna': Detección de actividad de Alfa-Larabinofuranosidasa». Tesis de mtría. Universidad Nacional del NORDESTE. Comunicaciones Científicas y Tecnológicas, Resumen: A-044.

Alleweldt, G. y F. Radler (1962). «Interrelationship between photoperiodic behavior of grapes \& growth of plant tissue cultures». En: Plant physiology 37.3, 376-379. Online:https : / / bit. ly / 3jkvsaH.

Alva-Guzmán, B., L. Cerna-Rebaza y J. Chico-Ruíz (2014). «Inducción de embriones somáticos a partir de hojas Capsicum chinensis utilizando diferentes concentraciones de 2, 4 Diclorofenoxiacético y 6 Bencilaminopurina». En: Scéndo 16.2. Online:https://bit.ly/2MHonCh.

Argüelles, A. y col. (2020). «Callogénesis in vitro de paprika (Capsicum annuum L.) cv. Papri King a partir de tallos». En: Big Bang Faustiniano 9.1, 4-7. Online:https://bit.ly/3nQdy0y.

Azcón-Bieto J. y Talon, M. (2008). Fisiología y Bioquíminca Vegetal. 2da Ed. Madrid: Hill - Interamericana.
Caballero, B., C. Márquez y B. Rojano (2017). «Efecto de la liofilización sobre las propiedades funcionales del ají rocoto (Capsicum pubescens)». En: Revista U.D.C.A. Actualidad \& Divulgación Científica 20.1, 111-119. Online:https: / / bit.ly / 2V5qwZI.

Espinosa, A. y col. (2012). «Efecto del tipo de explante y la concentración de ácido 2, 4diclorofenoxiacético en la formación de callos en Morus alba L.» En: Pastos y Forrajes 35.4, 407-416. Online:https:/ / bit.ly/3oQXStG.

Feeney, M. y col. (2007). «Shoot regeneration from organogenic callus of sweet cherry (Prunus avium L.)» En: Plant cell, tissue and organ culture 90.2, 201-214. Online:https:/ / bit.ly/3cKuUcT.

Feher, A., T. Pasternak y D. Dudits (2003). "Transition of somatic plant cells to an embryogenic state». En: Plant cell, tissue and organ culture 74.3, 201-228. Online:https:/ / bit.ly / 2Od2ZrJ.

Gómez, L. (2016). «Establecimiento de un protocolo para la inducción de la androgénesis en Capsicum chinense Jacq.» Tesis de Maestría. Mérida, Yucatán, México. Online:https: / / bit.ly / 2Pd2vjO: Centro de Investigación Científica de Yucatán.

Gutierrez-Rosati, A. y B. Vega (2017). «Micropropagación in vitro de "ají mirasol", Capsicum baccatum var. Pendulum». En: The biologist 14.2, 171-181. Online:https:/ / bit.ly/3pPkUTc.

Hernández, A. y H. Díaz (2019). «Inducción in vitro de callo embriogénico a partir del cultivo de anteras en "papa amarilla" Solanum goniocalyx Juz. \& Bukasov (Solanaceae)». En: Arnaldoa 26.1, 277-286. Online:https:/ / bit.ly/2YPyNFi.

Hernández, A., A. Pineda y H. Díaz (2019). «Efecto de la luz y del ácido giberélico en la germinación in vitro de Capsicum annuum L. cv. "Papri King".» En: Biotecnología Vegetal 19.3, 165-170. Online: https:/ / bit.ly/3ez5U5W.

Hernández, A., A. Pineda y H. Noriega (2019). «Aislamiento e identificación de Fusarium oxysporum obtenidos de zonas productoras de "ají paprika" Capsicum annumm L.(Solanaceae) en el distrito de Barranca, Perú». En: Arnaldoa 26.2, 689-698. Online:https://bit.ly/2YOy9HR.

Hernández, A. y col. (2020). «Efecto de la concentración de 2,4-diclorofenoxiactico en la inducción de callos in vitro utilizando cotiledones de rocoto (Capsicum pubescens Ruiz \& Pav.)» En: The Biologist 17.2, 327-334. Online:https: / / bit.ly / 3kXv5BM. 
Izquierdo, H., L. Alcaraz y M. Rodríguez-Álvarez (2017). «Micropropagación de chiltepín (Capsicum annuum L. cv.'glabriusculum') mediante el empleo de una oligosacarina de origen péctico». En: Acta universitaria 27.5, 34-43. Online:https:/ / bit.ly /2p9bTdE.

Larson, C., M. Gómez C.and Sánchez y D. Ríos (2006). «Inducción de caulogénesis indirecta en Eucalyptus globulus». En: Bosque 27.3, 250-257. Online:https:/ / bit.ly/3jriGXJ.

Levitus, G. y col. (2010). «Biotecnología y Mejoramiento Vegetal II». Tesis de mtría. Argentina: Instituto Nacional de Tecnología Agropecuaria.

Lucana, C. (2012). «Respuesta de 5 especies de Capsicum spp. A Phytophthora capsici Leon, bajo condiciones de invernadero, en los laboratorios de fitopatologia de la UNALM - Lima». Tesis de Ingeniera. Cusco. Perú. Online:https: / / bit.ly / 31J3taa: Universidad Nacional de San Antonio Abad del Cusco.

Marín, E. (2012). «Embriogénesis somática del género Capsicum: Validación de un protocolo de regeneración in vitro en Capsicum annuum». Tesis de Maestría. Mérida, Yucatán, México. Online:https: / / bit.ly / 2BHB7Ck: Centro de Investigación Científica de Yucatán.

Meiners, J., M. Schwab e I. Szankowski (2007). «Efficient in vitro regeneration systems for Vaccinium species». En: Plant Cell, Tissue and Organ Culture 89.2, 169-176. Online:https: / / bit.ly / 3cKCST3.

Müller, B. y J. Sheen (2007). «Advances in cytokinin signaling». En: Science 318.5847, 68-69. Online:https://bit.ly/3jutEvO.

Murashige, T. y F. Skoog (1962). «A revised medium for rapid growth and bio agsays with tohaoco tissue cultures». En: Physiology Plant 15.3, 473-497. Online:https://bit.ly/2MK33w2.

Orlinska, M. y P. Nowaczyk (2015). «In vitro plant regeneration of 4 Capsicum spp. genotypes using different explant types». En: Turkish Journal of Biology 39.1, 60-68. Online:https: / / bit.ly / 2MD8AHm.

Pérez, M. y col. (2009). «Expresión transitoria GUS en callos de arroz (var. J-104) mediante la optimización de las condiciones de cultivo in vitro». En: Rev. Colomb. Biotecnol. 9.2, 75-84. Online:https://bit.ly/2MIrERD.

Rashmi, R. y M. Trivedi (2014). «Effect of various growth hormone concentration and combination on callus induction, nature of callus and callogenic response of Nerium odorum». En: Applied biochemistry and biotechnology 172.5, 2562-2570. Online:https:/ / bit.ly/3cPoAkb.

Robledo, A. y G. Carrillo (2004). «Regeneración in vitro de plantas de Chile (Capsicum annuum L.) mediante cultivo de cotiledones e hipocótilos». En: Revista Fitotecnia Mexicana 27.2, 121-126. Online:https:/ / bit.ly /2pPgu4w.

Rodríguez, M. y col. (2014). «Inducción in vitro de callogénesis y organogénesis indirecta a partir de explantes de cotiledón, hipocótilo y hoja en Ugni molinae». En: Bosque 35.1, 111-118. Online:https://bit.ly/2WdJDCD.

Sala, F. y M. Labra (2003). «Encyclopedia Appl. Plant Sci.» En: ed. por B. Thomas, D. Murphy y B. Murray. Oxford, UK: Academic Press Elsevier. Cap. Somaclonal variation, págs. 1417-1422.

Sanatombi, K. y G. Sharma (2007). «Micropropagation of Capsicum annuum L». En: Notulae Botanicae Horti Agrobotanici Cluj-Napoca 35.1, 57-64. Online:https:/ / bit.ly/3cJKYeT.

Santana, N. (1982). «Determinacín de un medio adecuado para la obtención de callus en variedades de caña de azúcar (Saccharum species) in vitro.» En: Cultivos Tropicales 4.3, 48-52. Online:https:/ / bit.ly/3jmosdf.

Sardón, E. (2015). «Fortalecimiento de la cadena de valor del rocoto fresco (Capsicum pubescens) de la selva central para el mercado de Lima». Tesis de Maestría. Lima, Perú. Online:https:/ / bit.ly / 3gFCJ2Y: Universidad Nacional Agraria La Molina.

Shriram, V., V. Kumar y M. Shitole (2008). «Indirect organogenesis and plant regeneration in Helicteres isora L., an important medicinal plant». En: In Vitro Cellular and Developmental Biology-Plant 44.3, 186-193. Online:https:/ / bit.ly/31Go4vL.

Smith, R. (2012). Plant tissue culture: techniques and experiments. Londres, UK. Online:https: / / bit . ly/2qyukbU: Academic Press Elsevier.

Solís-Ramos, L. y col. (2010). «Indirect somatic embryogenesis and morphohistological analysis in Capsicum chinense». En: Biologia 65.3, 504-511. Online:https:/ / bit.ly/2MBI80E.

Taiz, L y E Zeiger (1998). Plant Physiology. 2nd. Sunderland, Massachusetts. Online:Online: https : / / bit.ly/35XfUTb: Sinauer Associates, Inc.

Terra, E. y col. (2009). "Controle da calogênese do paubrasil in vitro». En: Revista Árvore 33.6, 987-996. Online:https://bit.ly/2YSqBnD. 
Valdez, I. (2017). "Caracterización fenotípica de quince accesiones de germoplasma de rocoto (Capsicum pubescens Ruiz \& Pavón.) en la estación INIA Santa Rita Arequipa». Tesis de Ingeniera. Arequipa Perú. Online:https: / / bit.ly / 362Wo7K: Universidad Nacional de San Agustín,

Vélez, M. y col. (2010). «Obtención de plantas haploides en chile miahuateco (Capsicum annuum
L.)» En: Revista mexicana de ciencias agrícolas 1.2, 189-201. Online:https://bit.ly/3q6MoDO.

Venkataiah, P. y col. (2016). «Somatic embryogenesis and plant regeneration of Capsicum baccatum L.» En: Journal of Genetic Engineering and Biotechnology 14.1, 55-60. Online:https: / / bit.ly / 2JjhZyR. 